\title{
Spiritual Care Training for Mothers of Children with Cancer: Effects on Quality of Care and Mental Health of Caregivers
}

\author{
Somaieh Borjalilu ${ }^{1 *}$, Shahriar Shahidi ${ }^{1}$, Mohammad Ali Mazaheri ${ }^{1}$, Amir Hossein \\ Emami $^{2}$
}

\begin{abstract}
Background: The purpose of this study was to explore the effectiveness of a spiritual care training package in maternal caregivers of children with cancer. Materials and Methods: This study was a quasi-experimental study with pretest and posttest design consisting of a sample of $\mathbf{4 2}$ mothers of children diagnosed as having cancer. Participants were randomly assigned to either an experimental or a control group. The training package consisted of seven group training sessions offered in a children's hospital in Tehran. All mothers completed the Spirituality \& Spiritual Care Rating Scale (SSCRS) and the Depression, Anxiety and Stress Scale (DASS-21) at pre and post test and after a three month follow up. Results: There was significant difference between anxiety and spiritual, religious, Personalized care and total scores spiritual care between the intervention and control groups at follow-up $(\mathbf{P}<0.001)$.There was no statistically significant difference in stress and depression scores between the intervention and the control groups at follow-up. Conclusions: Findings show that spiritual care training program promotes spirituality, personalized care, religiosity and spiritual care as well as decreasing anxiety in mothers of children with cancer and decreases anxiety. It may be concluded that spiritual care training could be used effectively in reducing distressful spiritual challenges in mothers of children with cancer.
\end{abstract}

Keywords: Spiritual care training - mothers of children with cancer - quality of care - mental health - personalized care

Asian Pac J Cancer Prev, 17 (2), 545-552

\section{Introduction}

Childhood cancer is a chronic illness which claims millions of lives each year (Woodgate and Degner, 2003; Thomson, 2009). In Iran, depending on the region, the rate of childhood cancer is 48-112 and 51-114 per million in girls and boys, respectively. The rate of deaths from cancer is 42 in girls and 49 per million among boys (Mousavi et al., 2009).

Cancer is an unexpected and stressful event for children, adolescents and parents, which bring about challenges for both the patient and his / her family. Due to its chronic nature, cancer inflicts long-term treatment, physical disorders and mental distress on the patient (Cernvall et al., 2013; Kostak and Avci, 2013). Being diagnosed with cancer, therefore, sets off a state of crisis. Personal communications are disrupted because of uncertainty about the future and previous coping mechanisms seem insufficient. Also, hospitalization causes a despair phase in individuals and creates an emotion and spiritual crisis (Ebmeier et al., 1991; Highfield, 1992).

Spirituality refers to a universal human capacity for self-awareness, which is associated with a person's search for identification, and acquisition of meaning and purpose (Benson, 2006; Pargament and Sweeney, 2011). Hay and
Nay identified spirituality with 'relational conscious', an evolved human capacity for or an awareness of connections with self, others, the world and a transcendent power (Hay and Nye, 2006). Spiritual development is a lifelong process (Thomson, 2009). As such, children typically lead a strong spiritual life and once they are cognitively able to understand the different aspects of the 'self', they are able to grasp spirituality (Hart and Schneider, 1997; Woodgate and Degner, 2003).

When children are diagnosed with cancer, they may raise difficult questions to which they try to find the answer, such as why they are inflicted with the disease and why they suffer. Indeed, the first question that arises when a person suffers is 'why'; therefore, he or she may make attempts to search for the meaning of their suffering (Brant, 2010). They may make enquiries about God and why He has caused them to suffer. Children may also ask questions about death and its nature. Therefore, diseases speed up children's spiritual development (Shelly, 1982). In such cases, individuals need purpose to deal with crisis and the distress caused by these misfortunate events is rooted in one's inability to find meaning and purpose of life. As such, spiritual crisis may lead to lack of energy, anxiety, depression, unexplained pains, sorrow, lack of control over thoughts and emotions, and a sense of 
disengagement and isolation. Other consequences may include guilt feelings, anger, denial, helplessness and frustration (Shelly, 1982; Myers et al., 2014).

National Association for the Education of Young Children considers building interactions among family members as an effective strategy for promoting and supporting spiritual development in children (Heath et al., 2010) Parent's role is, therefore, of utmost importance in nurturing spirituality in children. In this sense, spiritual care is yet another care parents could provide in time of chronic diseases. American Cancer Society reported that family and spiritual care accounted for $35 \%$ of cancer survival rate (Hufton, 2006). As for the role of family, admittedly childhood diseases cause caregiver stress in the family (Taft et al., 2012).

The official diagnosis of a cancer causes parents to experience a spiritual crisis and a high level of anxiety (Fortier and Wanlass, 1984). Typically, families go through this stage by feeling anger, depression, a sense of duality, loss and of pressure, loneliness, difficulty in decision making, and uncertainty (Anderzen et al., 2010). Most hospitalized children, however, need the involvement of their parents for supporting them in the face of adversity, regarding their parents as the best source of support (Taft et al., 2012). Undoubtedly, parents who have confidence in their supporting role exhibit wider participation in the care of their hospitalized children. Such parents convey a sense of confidence and safety to their children, thereby enhancing their children's mental health and reducing the perception of pain (Kaplow and Hardin, 2007). Therefore, family members, particularly mothers, have a major role to play in supporting and providing emotional, social and spiritual needs of children (Woodgate and Degner, 2003; Abrams et al., 2007).

Spiritual care refers to supporting another person who is searching for meaning and purpose of life. It focuses on the individual who is anxious, in doubt or experiencing a sense of conflict. This care encompasses religious support (praying with the patient, talking to the patient about God, religious discussion with the patient, the patient's relationship with God and using religious texts), communication skills (establishing a real relationship with the patient, emotional support, bringing hope to the patient, encouraging the individual to express emotions, active listening and encouraging the patient toward positive thinking), empathic relationship with the patient (comforting the patient, showing him/her attention and care, openness to the patient's attitudes and feelings, and showing respect to him/her) (Narayanasamy, 2003). Accordingly, spirituality and spiritual care creates an opportunity for individuals with cancer to control the routinely portrayed psychological trauma of cancer (Balboni et al., 2007; Alcorn et al., 2010). Targeting individual spiritual beliefs, spirituality creates an important cognitive assessment in the coping mechanism for the patient, enabling him/her to evaluate negative events differently and to possess a stronger sense of control (Hart and Schneider, 1997).

Research suggests that spiritual beliefs and involvement in religious activities help children deal with sources of stress in life (Neuman, 2011). Conducting in-depth interviews with children of ages 5 to 12 years diagnosed with cancer, Pendleton, Cavalli, Pargament and Nasr demonstrated that spirituality could serve as a coping strategy (Pendleton et al., 2002). Studying the spiritual life of six and seven year old children with cancer Kamper and her colleagues found that the children considered God as the source of support and consolation and believe that God will help them during illness (Kamper et al., 2010). A survey on the need for spiritual care of hospitalized children in hospitals in the United States indicated that the children needed to deal with the pain and symptoms, needed a warm relationship with their parents, exhibited fear and aggression, needed to know why they were suffering, needed hope and compassion, and needed to know how death occurs. The results of the survey further showed that parents of hospitalized children also needed to cope with their children's pain and felt guilty and need to know whether the disease is a punishment for their sins (Foster et al., 2010a; Amrock and Weitzman, 2014).

Parents should, therefore, be capable of dealing with adverse conditions of their children in time of disease, as accepting the misfortune is more difficult for the parents (Long et al., 2014). Thus, parents needs to be empowered to provide comprehensive care for their children, as during this time the parents themselves face existential crisis and need to meet their spiritual needs. Accordingly, parents need to reach tranquility in the first place and try to find meaning for the mishap. Only then they can provide care and support for their children. Parents need to have the ability, skill and knowledge to care for their children (Hanington et al., 2010). In the current research, we were, therefore, concerned with investigating whether educating parents on spiritual care is effective in their spiritual care skills and whether it improves mother's mental health.

\section{Materials and Methods}

\section{Study subjects}

This study was a quasi-experimental study with pretest and posttest design. Participants consisted of 42 mothers of children with cancer residing in Tehran province. They were aged 21 to 52 years old $(M=34.1, S D=9.45)$. The inclusion criteria included: age of the child (7 - 15 years), diagnosis of cancer by a pediatric oncologist, the child must have given radiotherapy for at least one month, the child should not be under any psychotropic medication, and that the mother should be the primary and legitimate caregiver. 42 mothers of child cancer were selected randomly by cluster sampling method from two children's hospitals in Tehran. After coordination with officials in these hospitals, eligible participants were identified. Researchers then communicated with mothers, briefing them on the research purpose and the design. Finally, the participants gave their written consent to participate in the study. This study was conducted with the approval from the Faculty of Psychology and Education Ethics Committee in Shahid Beheshti University in Tehran. Ethics Committee's approval letter number.

\section{Intervention procedure}

A total of 42 mothers were randomly assigned to a 
Spiritual Care Training for Mothers of Children with Cancer: Effects on Quality of Care and Mental Health of Caregivers

control and an experimental group ( $\mathrm{n}=21$ in each group). The participants were then informed of the group training sessions. The training sessions were scheduled for March 2014 in three groups of seven participants. The entire training period lasted for two months. The control group remained on a waiting list and in accordance with requirements for research ethics, received training identical to the experimental group after the follow up period was over. The follow-up was performed three months after completion of the intervention.

The Educational aspect of the spiritual care training package for parents of children with cancer was provided by Borjalilu, Shahidi, Mazaheri and Fathabadi and used for the education component of the intervention (Borjalilu, 2014). This was based on the spiritual care training package, ASSET model (Actioning Spirituality and Spiritual Care Education and Training) (Narayanasamy, 1999). Major skills for spiritual care in this model are communication skills, encouragement and offering hope. The present model was, however, modified in conformity with local customs, beliefs and accepted norms. The package is primarily concerned with psychoeducational therapy which integrates psychotherapeutic and educational interventions (Lukens and McFarlane, 2006). The final version was then developed using expert judgments and opinions of some caregivers of children with cancer (Borjalilu, 2014). In each judgment session, the degree of agreement between experts and caregivers was over .8. Cohen's kappa for the inter-rater agreement of the whole training package was 0.992 . Table 1 summarizes the contents used in the training package.

This training package encompassed seven 90-minute sessions offered once a week. It involved questions and answers, brainstorming, model presentation and group discussion. Parents were assisted to think about the misfortune they faced. Both control and experimental groups were subjected to pre-test, a week before the treatment, and post-test, a week after the treatment, using SSCRS and DASS-21. The results were reanalyzed three month after the last session of treatment using SSCRS.

\section{Data collection tools}

Spirituality \& Spiritual Care Rating Scale (SSCRS). Developed by Mc Sherry et al. (2002), it is an instrument investigating and measuring spirituality and spiritual care. The questionnaire was developed based on a 5-point Likert scale. Following the preliminary pilot of the questionnaire, some items were removed, making it a 17-item scale. The final scale consisted of four major factors of spirituality, spiritual care, religiosity and personalized care. Exploratory factor analysis was used to evaluate the reliability. Principal component analysis of the scale revealed that eigenvalues of the 4 factors were greater than 1 and that the cumulative percentage of variance accounted for by the current and all preceding principal components was 57\% 0.32. Cranach's Alpha for spirituality, spiritual care, religiosity and personalized care were $0.60,0.67,0.90$ and 0.82 , respectively. Test-retest reliability coefficients were $0.57,0.77,0.85$ and 0.72 for spirituality, spiritual care, religiosity and personalized care, respectively $(\mathrm{p}<0.01)$.

Depression, Anxiety and Stress Scale (DASS-21). DASS (Lovibond and Lovibond, 1995) is a set of three self-report scales designed to measure the negative emotional states of depression, anxiety and stress. The short version, the DASS-21, is a 21-item questionnaire on a 4-point Likert scale. Acceptable estimates of reliability were obtained for the scale as a whole via internal consistency and test re-test reliability. Cranach's Alpha for depression, anxiety and stress were $0.89,0.85$ and 0.83 , respectively. Also, test-retest reliability coefficients were $0.80,0.76$ and 0.81 for depression, anxiety and stress respectively $(\mathrm{p}<0.01)$.

\section{Statistical analysis}

Statistical analyses mainly used the descriptive statistical analyses. Descriptive data were expressed as mean \pm SD (standard deviation). Analysis of variance (ANOVA) was used to ascertain the significance of differences between continuous variables and tested by repeated measures. Differences with $\mathrm{P}<0.01$ were considered significant. Data were analyzed with SPSS version 17.0 for Windows (SPSS Inc., Chicago, IL).

\section{Results}

The 42 mothers (age range: 21-52 years) were asked to participate in this study, assigned in experimental group $\left(\mathrm{M}_{\mathrm{age}}=36.8\right.$ years $)$ and the control $\left(\mathrm{M}_{\mathrm{age}}=31.9\right.$ years $)$. For the compare the DASS-21 of experimental and control groups in posttest, AVCOVA was used. Its results have reported in Table 2.

\section{Table 1. Spiritual Care Training Package Designed for Parents of Children with Cancer}

\begin{tabular}{|c|c|c|}
\hline Session & Subject & Content \\
\hline 1 & Spirituality & $\begin{array}{l}\text { Introduction to concepts of spirituality and spiritual awareness and familiarity with } \\
\text { religious coping strategies }\end{array}$ \\
\hline 2 & Spirituality and children & $\begin{array}{l}\text { Spirituality in children, familiarity with children's spiritual needs, recognition of spiritual } \\
\text { crisis in sick children and spiritual care }\end{array}$ \\
\hline 3 & Relationship & $\begin{array}{l}\text { Familiarity with secure and insecure attachment patterns and with attachment behavior. } \\
\text { Exploration of mother-child interaction }\end{array}$ \\
\hline 4 & Excitements & $\begin{array}{l}\text { Familiarity with excitements, causes and behavioral manifestations, recognition of } \\
\text { excitements of children with cancer, how to deal with these excitements in time of disease }\end{array}$ \\
\hline 5 & Hope and future & $\begin{array}{l}\text { Promoting self-confidence, sense of independence and self-sufficiency, familiarity with } \\
\text { rules of the play as to create a fun and exhilarating environment for children }\end{array}$ \\
\hline
\end{tabular}


Table 2. The Result of ANCOVA for Comparing Depression, Anxiety and Stress of Experimental and Control Groups

\begin{tabular}{|c|c|c|c|c|c|c|c|}
\hline \multirow[b]{2}{*}{ DASS } & \multicolumn{3}{|c|}{ experimental group } & \multicolumn{3}{|c|}{ Control group } & \multirow[b]{2}{*}{$\begin{array}{l}\text { Pre : Post } \\
\text { time effect }\end{array}$} \\
\hline & $\begin{array}{c}\text { PER (baseline) } \\
\text { Mean (SD) }\end{array}$ & $\begin{array}{c}\text { POST } \\
\text { Mean (SD) }\end{array}$ & $\begin{array}{l}\text { After } 3 \\
\text { months }\end{array}$ & $\begin{array}{c}\text { PER } \\
\text { Mean (SD) }\end{array}$ & $\begin{array}{c}\text { POST } \\
\text { Mean (SD) }\end{array}$ & $\begin{array}{l}\text { After } 3 \\
\text { months }\end{array}$ & \\
\hline Stress & $2.71(0.148)$ & $2.37(0.194)$ & $2.18(0.144)$ & $2.67(0.12)$ & $2.58(0.152)$ & $2.48(0.148)$ & $\begin{array}{l}F=18.01 \\
P<0.001 \\
\eta 2=0.51\end{array}$ \\
\hline Anxiety & $2.7(0.053)$ & $2.54(0.14)$ & $2.42(0.068)$ & $2.68(0.185)$ & $2.65(0.11)$ & $2.65(0.104)$ & $\begin{array}{l}F=4.009 \\
P<0.001 \\
\eta 2=0.45\end{array}$ \\
\hline Depression & $2.68(0.132)$ & $2.47(0.116)$ & $2.4(0.116)$ & $2.63(0.105)$ & $2.6(0.086)$ & $2.62(0.101)$ & $\begin{array}{l}F=41.49 \\
P<0.001 \\
\eta 2=0.35\end{array}$ \\
\hline
\end{tabular}

Table 3. The Result of ANCOVA for Comparing Spirituality and Spiritual Care of Experimental and Control Group

\begin{tabular}{|c|c|c|c|c|c|c|c|}
\hline \multirow[b]{2}{*}{ SSCRS } & \multicolumn{3}{|c|}{ Experimental Group } & \multicolumn{3}{|c|}{ Control Group } & \multirow[b]{2}{*}{$\begin{array}{l}\text { Pre : Post } \\
\text { time effect }\end{array}$} \\
\hline & $\begin{array}{c}\text { PER (baseline) } \\
\text { Mean (SD) }\end{array}$ & $\begin{array}{c}\text { POST } \\
\text { Mean (SD) }\end{array}$ & $\begin{array}{l}\text { After } 3 \\
\text { months }\end{array}$ & $\begin{array}{c}\text { PER } \\
\text { Mean (SD) }\end{array}$ & $\begin{array}{c}\text { POST } \\
\text { Mean (SD) }\end{array}$ & $\begin{array}{l}\text { After } 3 \\
\text { months }\end{array}$ & \\
\hline Spirituality & $3.73(0.015)$ & $3.93(0.037)$ & $4.022(.034)$ & $3.72(0.013)$ & $3.75(0.033)$ & $3.74(0 / 03)$ & $\begin{array}{l}F=9.09 \\
P<0.00 \\
\eta 2=0.58\end{array}$ \\
\hline Religiosity & $3.5(0.007)$ & $3.51(0.006)$ & $3.73(0.01)$ & $3.51(0.046)$ & $3.52(0.01)$ & $3.54(0 / 009)$ & $\begin{array}{c}F=25.71 ; \\
P<0.001 ; \\
\eta 2=0.66\end{array}$ \\
\hline $\begin{array}{l}\text { Personalized } \\
\text { care }\end{array}$ & $2.21(0.052)$ & $2.96(0.079)$ & $3.04(0.079)$ & $2.19(0.046)$ & $2.24(0.07)$ & $2.26(0 / 07)$ & $\begin{array}{c}F=7.65 \\
P<0.001 \\
\eta 2=0.43\end{array}$ \\
\hline Spiritual care & $3.49(0.038)$ & $4.16(0.04)$ & $4.22(0.037)$ & $3.5(0.034)$ & $3.53(0.035)$ & $3.53(0 / 033)$ & $\begin{array}{c}F=6.97 \\
P<0.004 \\
\eta 2=0.73\end{array}$ \\
\hline
\end{tabular}

Table 2 shows the changes Depression, Anxiety and Stress scores of the intervention and control groups. The score of stress in the intervention group decreased in the post test and there was also a trend reduction in number of stress until 3 months after the program (the mean scores were 2.71 at pre-test, 2.37 post-test and 2.18 three months after receiving education). In the control group, significant differences were not identified during the 3-months follow up (corresponding scores were $2.67,2.58$ and 2.48 respectively). There were significant differences interaction between groups and time in pre and post test $(\mathrm{F}=18.01 ; \mathrm{P}<0.001 ; \eta 2=0.51)$, but no significant differences interaction between groups and time in 3-months follow up $(\mathrm{F}=2.64 ; \mathrm{P}=0.114)$. In the control group, not significant differences interaction between groups and time.

The anxiety scores in the intervention group decreased in the post test and there was also a trend reduction in number of stress until 3 months after the program (the mean scores were 2.7 at pre test, 2.54 at post test, and 2.42 three months after receiving education). There were significant differences interaction between groups and time in pre and post test $(\mathrm{F}=4.009 ; \mathrm{P}<0.001 ; \eta 2=0.45)$ and significant differences interaction between groups and time in 3-months follow up $(\mathrm{F}=5.943 ; \mathrm{P}<0.001)$.
Result showed that education program favorably affected anxiety of mother's child cancer. In the control group, not significant differences interaction between groups and time.

The score of depression in the intervention group decreased in the post test and there was also a trend reduction in number of stress until 3 months after the program (corresponding scores were 2.68, 2.27 and 2.4 respectively). There were significant differences interaction between groups and time in pre and post test $(\mathrm{F}=41.49 ; \mathrm{P}<0.001 ; \eta 2=0.35)$, but no significant differences interaction between groups and time in 3 -months follow up $(\mathrm{F}=29.86 ; \mathrm{P}=0.123)$. In the control group, significant differences were not significant differences interaction between groups and time.

Table 3 shows the changes Spirituality and Spiritual Care scores of the intervention and control groups. The score of Spirituality in the intervention group increased in the post test and there was also a trend increased in number of stress until 3 months after the program (the mean scores were 3.73 at pre-test, 3.39 post-test and 4.022 three months after receiving education). There were significant differences interaction between groups and time in pre and post test $(\mathrm{F}=9.09 ; \mathrm{P}<0.00 ; \eta 2=0.58)$, and significant differences interaction between groups and 
Spiritual Care Training for Mothers of Children with Cancer: Effects on Quality of Care and Mental Health of Caregivers

time in 3-months follow up $(\mathrm{F}=18.34$; $\mathrm{P}<0.001)$. In the control group, significant differences were not significant differences interaction between groups and time.

The Religiosity scores in the intervention group increased in the post test and there was also a trend reduction in number of stress until 3 months after the program (the mean scores were 3.5 at pre test, 3.51 at post test, and 3.73 three months after receiving education). There were significant differences interaction between groups and time in pre and post test $(\mathrm{F}=25.71 ; \mathrm{P}<0.001$; $\eta 2=0.66$ ), and significant differences interaction between groups and time in 3-months follow up $(\mathrm{F}=5.71 ; \mathrm{P}<0.001)$. In the control group, significant differences were not significant differences interaction between groups and time.

The score of Personalized care in the intervention group increased in the post test and there was also a trend reduction in number of stress until 3 months after the program (corresponding scores were 2.21, 2.19 and 3.04 respectively). There were significant differences interaction between groups and time in pre and post test $(\mathrm{F}=7.65 ; \mathrm{P}<0.001 ; \eta 2=.43)$, and significant differences interaction between groups and time in 3-months follow up $(\mathrm{F}=5.82 ; \mathrm{P}<0.001)$. In the control group, significant differences were not significant differences interaction between groups and time.

The total score of spiritual care the participants in the intervention group improved during the two weeks after the education and slightly increased during the three months follow up $(3.49,4.16$, and 4.22). No considerable changes were observed in the total spiritual care score of the control group during the follow up period $(3.5,3.53$, and 3.53 , respectively). There were significant differences interaction between groups and time in pre and post test $(\mathrm{F}=6.97 ; \mathrm{P}<0.004 ; \eta 2=0.73)$, and significant differences interaction between groups and time in 3-months follow up $(\mathrm{F}=20.12 ; \mathrm{P}<0.004)$. In the control group, significant differences were not significant differences interaction between groups and time.

\section{Discussion}

The present research was concerned with exploring the effectiveness of educating mothers of children with cancer in spiritual care with the aim of improving their mental health and spiritual care skills. The results revealed that such training did indeed change mothers' attitude towards spirituality and spiritual care in the experimental group and that this effect remained constant at follow-up. According to the ASSET model (Narayanasamy, 1999), teaching spiritual care on a personal level develops self-awareness (knowledge of spiritual attitudes and beliefs of the self) and spiritual health. Such training further raises awareness of spirituality and its domains, spiritual care, values and the concept of spirituality, and develops empowerment in recognizing and evaluating spiritual needs and establishing relationship with the patient (Chan, 2010; Foster et al., 2010b). The ASSET encourages caregivers to become sensitive to the patient's spiritual needs, reduces spiritual stress and promotes the quality of spiritual care (Carson, 2011; Cone and Giske, 2013). As the most fundamental pillar in society, family is responsible for providing appropriate health care to the patient and her companions (Park, 2010). In providing care for the patient, the family needs a clear understanding of the disease and of the required care. With profound advances in hygiene, health care institutions have given way to family-centered care (Smith et al., 2015). In this sense, spiritual care has been regarded as a duty of caregivers in medical settings (Zollfrank et al., 2015)

Deborah and Elaine showed that diagnosis of a disease in the child causes mothers to feel guilty and experience a sense of isolation and punishment by God (because of past sins), thus developing resentment toward God and making attempts to search for the meaning of their children's suffering (Allen and Marshall, 2010). Familiarity with the concepts of spirituality and self-awareness could encourage mothers to connect with a transcendent power (God), self (forgiveness) and others, hence experiencing peace of mind. Similarly, Hexem and her colleagues demonstrated that mothers believed that religiosity gave meaning to their lives and was a source of support, peace and relief; the source was believed to be God or a transcendent power (Hexem et al., 2011). Styling the needs of patients and caregivers, Taylor and Mamier found that patients and caregivers need time to relax and talk about spiritual resources (Taylor and Mamier, 2005).

In the present study, it was shown that the effect of spiritual care education in the experimental group was significantly different from that in the control group and that there was a significant difference between performance of experimental group and control group in the post-test.

In the proposed training program, mothers were initially familiarized with the concept of spirituality and spiritual needs as to promote self-awareness. Indeed, we intended to encourage mothers to embark on an introspection of the self, too look inside. Introductory sessions, therefore, targeted an assortment of issues: connection with God or a deity (Trusting God and soliciting help from Him), characterization meaning and life goals (a holistic perspective toward life, coming back to life, being realistic about the misfortune - the child's disease - and setting new goals according to the current conditions), courage and hope (accepting the new conditions and living for the moment, giving up trying to control the uncontrollable, having faith, thinking positively and considering new possibilities), peace (creating a private self-enclosed environment, seizing the day and living life fully), exploring life beauties (appreciating nature and its beauties, art and music), respect and attention (unconditional acceptance, relationship with the self and others, expressing love and being dearly loved, and forgiveness). Covering these issues, we hoped to encourage the mothers to gain a new perspective on spirituality and personalized care.

The next step was the introduction of the following issues in the psycho education program: Children's spiritual growth, spiritual needs, and recognition of spiritual crisis in children. This was done in order to empower mothers in providing spiritual care to their children. This was followed by a discussion on intellectual challenges 
children may face, such as the meaning of suffering, pain and the concept of death. The skills required for an effective mother-child relationship were also presented. Identifying emotions in children with cancer and how to deal with emotions were other issue discussed during the training session. Mothers were educated on strategies to raise hope in their children by improving their self-esteem and how to create a happy environment. In the light of the preparations offered in the training program, mothers gained a working knowledge on how to cope with the conditions of children with cancer; following the training program (post-test), mothers understanding was shown to be significantly different from that before the program (pre-test) $(\mathrm{p}<0.01)$.

Religiosity was yet another important issue considered in educating mothers on spiritual care, as it is a pivotal issue people reflect upon in adversity. According to the theory of stress and coping (Bambara et al., 2009), individuals adopt different coping strategies to deal with distress. Religion can serve as a support source to reduce adverse effects of stress (Lim and Zebrack, 2004). Whereas positive religious coping is characterized by a sense of spiritual connection with God (or a deity) and others and having meaning in life, negative religious coping represents weak connection with a deity and a pessimistic view of the world.

Caregivers' coping strategies involve creating a philosophy for life, optimism and hope through religious teachings (Atkin and Ahmad, 2000; Rocha-Garcia et al., 2003). Religion, worship and faith serve an important support source for mothers (Patistea, 2005; Fletcher et al., 2010). A number of studies have shown that Muslim caregivers of children with cancer employed religious coping as a parental coping strategy (Sposito et al., 2015). Perricone and her colleagues found that mothers of children with cancer and chronic disease tried and controlled their distress by praying for their children (Banerjee et al., 2011; Perricone et al., 2013). Research suggests that adaptive caregivers exhibit a higher degree of positive religious coping and, expectedly, a lower degree of negative religious coping, compared to their maladaptive counterparts.

Another result in this study, it was showed effect of training spiritual care on mental health of mothers of child cancer. Therefore observed high scores of depression, anxiety and stress in mothers of children with cancer, because cancer in children is one of the most stressful events that mothers experience. (Masa'Deh et al., 2012; Naderi et al., 2012). Their Children threatened with death and they feel that in this event they are unable to control affairs. (McCarthy et al., 2009; Witt et al., 2010).

As the results showed in the experimental group of mothers, spiritual care training had a significant effect in reducing of anxiety, depression and stress. As mentioned before, one of the objectives of Training courses was consciousness. Mothers rely on their own beliefs and values; browse more of their religious and spiritual. This led to reduce the anxiety; depression and stress in the mothers' experimental group, because spirituality and religion are as a resource for coping with challenges and difficulties (Jim et al., 2006; Park, 2010) and also there is a relationship between the search for the meaning of life and mental health.

In the present study the aspects of cognitive, behavioral and spiritual experience of mothers of children with cancer were given. The cognitive aspect of the search for meaning and purpose of life was considered. In Experimental aspects, feeling of hope, love, and connection was considered, and in a Behavioral aspect was praying (Holder et al., 2010).

It seems that the spiritual care training in the field of Cognitive by some mechanisms such as Let's go (Nash et al., 2013) thinking about the present that was emphasized in training sessions, cause To reduce the unpleasant feeling of anxiety, threaten and impacted. So the mothers were encouraged that to attend present time and have paid all their efforts for their child. Thinking about Today's events and activities can make a distance to thinking of anxiety field.

On the other hand, one of the factors to reduce stress, anxiety and depression in mothers of children with cancer, was activation of spiritual coping strategies such as trust, patience, leaving the problem to God that are in our Islamic teachings, because when human is sure about near God Trust and belief in His wisdom created. In the Quran, God describes believers "I will submit my work to God, the Lord is aware of servants". So the delegation of the affairs is leaving the affairs to God without cause, the official man submit to the will of God. Acceptance of God's will, create a kind of friendship and love between God and human that man was resistant to accept the suffering of life (Bonab and Koohsar, 2011; Mousavi et al., 2015). Therefore, they will free from any threat, fear and stress and feel comfortable (Gaudette and Jankowski, 2013).

As the results show that education is the cause of reducing depression in the experimental group. Hospitalization for sick children in hospitals are often self-blames their mothers. These mothers often are less optimistic about future (Wray et al., 2011; Krattenmacher et al., 2014). This phenomenon is very important in chronic diseases such as cancer. Because, as mentioned earlier their children threatened to death and mothers feel powerless. (Kudubes et al., 2013). All subjects said confirm the high score on the depression test in two experimental and control groups of the present study. But it seems that the use of cognitive skills against spiritual such as drawing goals for the future (improved patient child and support family members), Trying to achieve the stated objectives, forgive yourself and others and to avoid self-blame, led reform in these maternal negative emotional responses and are reduced feelings of sadness, helplessness and hopelessness (Koons, 2012). On the one hand, it seems that according to Islamic teachings, such as the hope for divine mercy and healing in their children reduced a sense of emptiness. Have a positive outlook help mothers to improve their hope (Han et al., 2009; Garcini et al., 2013).

But the lack of significant stress and depression during the follow-up can be because of stress occurs essentially against the existence of some external conditions, such as disease, and as long as these conditions persist, there may also be stress. Also spiritual care for mothers is a short 
Spiritual Care Training for Mothers of Children with Cancer: Effects on Quality of Care and Mental Health of Caregivers

term that has positive impact but external conditions, the existence of child illness, still exist. This post-treatment period also causing stress and depression may be deeply rooted in the people.

Religion provides individuals with a systematic approach for coping with stressors in life. Admittedly, religious coping strategies may be considered to be largely culture specific (Jim et al., 2015). This is vividly observable in the socio-cultural context of Iran. In this study, prior to the performance of psycho educational intervention, religious beliefs and practices in the experimental group was assessed (Pargament, 2001). Drawing on the approach, we tried to carry out a religious evaluation in order to adjust and reconstruct a stressful event. The experiences of mothers were also used to discuss spiritual coping strategies, such as faith, patience, and submission to God's will. Accordingly, they were assisted to participate in religious practices, such as visiting holy places, prayer or worship, as to keep stressors away and to solicit God's help.

The results showed that empowering mothers in spiritual care strengthened their spiritual beliefs and educated them on spiritual care skills. Though intrigued by the psycho educational program, the majority of mothers failed to attend the program, as the process of cancer diagnosis and treatment requires around the clock care by mothers. As such, empowering mothers of children with cancer calls for modern techniques of training, such as distance education. Examples include designing educational CDs and taking advantage of the cyberspace. Most countries offer online assistance for educating mothers of children diagnosed with cancer, so mothers could benefit from the available information and also share their experiences. Therefore, there are increasing calls for such new techniques in educating mothers of children with chronic and oncological disease.

\section{References}

Abrams AN, Hazen EP, Penson RT (2007). Psychosocial issues in adolescents with cancer. Cancer Treat Rev, 33, 622-30.

Alcorn SR, Balboni MJ, Prigerson HG, et al (2010). "If God wanted me yesterday, I wouldn't be here today": Religious and spiritual themes in patients' experiences of advanced cancer. J Palliative Med, 13, 581-8.

Allen D, Marshall ES (2010). Spirituality as a coping resource for African American parents of chronically ill children. MCN Am J Matern Child Nurs, 35, 232-7.

Amrock SM, Weitzman M (2014). Parental psychological distress and children's mental health: results of a national survey. Acad Pediatr, 14, 375-81.

Anderzen-Carlsson A, Kihlgren M, Svantesson M, et al (2010). Parental handling of fear in children with cancer; caring in the best interests of the child. J Pediatric Nurs, 25, 317-26.

Atkin K, Ahmad WI (2000). Family care-giving and chronic illness: how parents cope with a child with a sickle cell disorder or thalassaemia. Health Soc Care Community, $\mathbf{8}$, 57-69.

Balboni TA, Vanderwerker LC, Block SD, et al (2007). Religiousness and spiritual support among advanced cancer patients and associations with end-of-life treatment preferences and quality of life. J Clin Oncol, 25, 555-60.

Bambara JK, Owsley C, Wadley V, et al (2009). Family caregiver social problem-solving abilities and adjustment to caring for a relative with vision loss. Invest Ophthalmol Vis Sci, 50, 1585-92.

Banerjee AT, Watt L, Gulati S, et al (2011). Cultural beliefs and coping strategies related to childhood cancer: the perceptions of South Asian immigrant parents in Canada. J Pediatr Oncol Nurs, 28, 169-78.

Benson PL (2006). The science of child and adolescent spiritual development: Definitional, theoretical, and field-building challenges. Handbook Spiritual Develop Childhood Adolescence, 484-97.

Bonab BG, Koohsar AAH (2011). Reliance on God as a core construct of Islamic psychology. Procedia-Social Behavioral Sci, 30, 216-20.

Borjalilu S, Shahidi S, Mazaheri MA, Fathabadi J, Emammei AH (2014). The effectiveness of spiritual care base parent training on quality of life, perceived pain and mental health component in children with cancer, [PhD thesis]. School of psychology, University of Shahid Beheshti University.

Brant JM (2010). The global experience of cancer pain. Asian Pac J Cancer Prev, 11, 7-12.

Carson VB (2011). What is the essence of spiritual care? JChrist Nurs, $28,173$.

Cernvall M, Carlbring P, Ljungman G, et al (2013). Guided selfhelp as intervention for traumatic stress in parents of children with cancer: conceptualization, intervention strategies, and a case study. J Psychosoc Oncol, 31, 13-29.

Chan MF (2010). Factors affecting nursing staff in practising spiritual care. J Clin Nurs, 19, 2128-36.

Cone PH, Giske T (2013). Teaching spiritual care-a grounded theory study among undergraduate nursing educators. J Clin Nurs, 22, 1951-60.

Ebmeier C, Lough MA, Huth MM, et al (1991). Hospitalized school-age children express ideas, feelings, and behaviors toward God. J Pediatric Nurs, 6, 337-49.

Fletcher PC, Schneider MA, Harry RJ (2010). How do I cope? Factors affecting mothers' abilities to cope with pediatric cancer. J Pediatr Oncol Nurs, 27, 285-98.

Fortier LM, Wanlass RL (1984). Family crisis following the diagnosis of a handicapped child. Family Relations, 13-24.

Foster TL, Lafond DA, Reggio C, et al (2010a). Pediatric palliative care in childhood cancer nursing: from diagnosis to cure or end of life. Semin Oncol Nurs, 26, 205-21.

Foster TL, Lafond DA, Reggio C, et al Pediatric palliative care in childhood cancer nursing: from diagnosis to cure or end of life. Seminars in oncology nursing, 2010b. Elsevier, 205-21.

Garcini LM, Short M, Norwood WD, et al (2013). Affective and motivational predictors of perceived meaning in life among college students. J Happiness Well-Being, 1, 0-.

Gaudette H, Jankowski KR (2013). Spiritual coping and anxiety in palliative care patients: A pilot study. J Health Care Chaplaincy, 19, 131-9.

Han H-R, Cho EJ, Kim D, et al (2009). The report of coping strategies and psychosocial adjustment in Korean mothers of children with cancer. Psychol Oncol, 18, 956.

Hanington L, Ramchandani P, Stein A (2010). Parental depression and child temperament: assessing child to parent effects in a longitudinal population study. Infant Behav Dev, 33, 88-95.

Hart D, Schneider D (1997). Spiritual care for children with cancer. Sem Oncol Nursing, 13, 263-70.

Hay D, Nye R (2006). The Spirit of the Child, Jessica Kingsley Publishers.

Heath JA, Clarke NE, Donath SM, et al (2010). Symptoms and suffering at the end of life in children with cancer: an Australian perspective. Med J Australia, 192, 71.

Hexem KR, Mollen CJ, Carroll K, et al (2011). How parents 
Somaieh Borjalilu et al

of children receiving pediatric palliative care use religion, spirituality, or life philosophy in tough times.J Palliat Med, 14, 39-44.

Highfield MF (1992). Spiritual health of oncology patients: Nurse and patient perspectives. Cancer nursing, 15, 1-8.

Holder MD, Coleman B, Wallace JM (2010). Spirituality, religiousness, and happiness in children aged 8-12 years. $J$ Happiness Studies, 11, 131-50.

Hufton E (2006). Parting gifts: the spiritual needs of children. $J$ Child Health Care, 10, 240-50.

Jim HS, Pustejovsky JE, Park CL, et al (2015). Religion, spirituality, and physical health in cancer patients: A metaanalysis. Cancer.

Jim HS, Richardson SA, Golden-Kreutz DM, et al (2006). Strategies used in coping with a cancer diagnosis predict meaning in life for survivors. Health Psychol, 25, 753.

Kamper R, Van Cleve L, Savedra M (2010). Children with advanced cancer: responses to a spiritual quality of life interview. J Spec Pediatr Nurs, 15, 301-6.

Kaplow R, Hardin SR 2007. Critical care nursing: synergy for optimal outcomes, Jones Bartlett Learning.

Kostak MA, Avci G (2013). Hopelessness and depression levels of parents of children with cancer. Asian Pac J Cancer Prev, 14, 6833-8.

Krattenmacher T, Kühne F, Halverscheid S, et al (2014). A comparison of the emotional and behavioral problems of children of patients with cancer or a mental disorder and their association with parental quality of life. J Psychosom Res, 76, 213-20.

Kudubes AA, Bektas M, Ugur O (2013). Symptom frequency of children with cancer and parent quality of life in Turkey. Asian Pac J Cancer Prev, 15, 3487-93.

Lim JW, Zebrack B (2004). Caring for family members with chronic physical illness: a critical review of caregiver literature. Health Qual Life Outcomes, 2, 50.

Long KA, Keeley L, Reiter-Purtill J, et al (2014). Child-rearing in the context of childhood cancer: perspectives of parents and professionals. Pediatr Blood Cancer, 61, 326-32.

Lovibond PF, Lovibond SH (1995). The structure of negative emotional states: comparison of the depression anxiety stress scales (DASS) with the beck depression and anxiety inventories. Behaviour research and therapy, 33, 335-43.

Lukens EP, McFarlane WR (2006). Psychoeducation as Evidence-Based Practice. Foundat Evidence-Based Social Work Practice, 291.

Masa'Deh R, Collier J, Hall C (2012). Parental stress when caring for a child with cancer in Jordan: a cross-sectional survey. Health Quality Life Outcomes, 10, 88-95.

McCarthy MC, Clarke NE, Vance A, et al (2009). Measuring psychosocial risk in families caring for a child with cancer: The psychosocial assessment tool (PAT2. 0). Pediatric Blood Cancer, 53, 78-83.

McSherry W, Draper P, Kendrick D (2002). The construct validity of a rating scale designed to assess spirituality and spiritual care. Int J Nurs Stud, 39, 723-34.

Mousavi FS, Bonab BG, Karimi JP, et al (2015). The role of trusting in god in predicting mental health of tehran university students. Health, Spirituality Med Ethics, 1.

Mousavi SM, Gouya MM, Ramazani R, et al (2009). Cancer incidence and mortality in Iran. Ann Oncol, 20, 556-63.

Myers RM, Balsamo L, Lu X, et al (2014). A prospective study of anxiety, depression, and behavioral changes in the first year after a diagnosis of childhood acute lymphoblastic leukemia. Cancer, 120, 1417-25.

Naderi M, Moghadam MF, Hamzenejad M, et al (2012). Posttraumatic stress disorder and related factors in parents of children with cancer in south-east of Iran. Iranian Red
Crescent Med J, 14, 776 .

Narayanasamy A (1999). Learning spiritual dimensions of care from a historical perspective. Nurse Education Today, 19, 386-95.

Narayanasamy A (2003). Spiritual coping mechanisms in chronic illness: A qualitative study. Br J Nurs, 11, 1461-70.

Nash P, Darby K, Nash S (2013). The spiritual care of sick children: reflections from a pilot participation project. Int $J$ Children's Spirituality, 18, 148-61.

Neuman ME (2011). Addressing children's beliefs through Fowler's stages of faith. J Pediat Nurs, 26, 44-50.

Pargament KI (2001). The psychology of religion and coping: Theory, research, practice, Guilford Press.

Pargament KI, Sweeney PJ (2011). Building spiritual fitness in the army: an innovative approach to a vital aspect of human development. Am Psychol, 66, 58.

Park M (2010). Understanding complexity of Asian American family care practices. Arch Psychiatric Nurs, 24, 189-201.

Patistea E (2005). Description and adequacy of parental coping behaviours in childhood leukaemia. Int J Nurs Stud, 42, 283-96.

Pendleton SM, Cavalli KS, Pargament KI, et al (2002). Religious/spiritual coping in childhood cystic fibrosis: A qualitative study. Pediatrics, 109, 8 .

Perricone G, Guerra MP, Cruz O, et al (2013). Maternal coping strategies in response to a child's chronic and oncological disease: a cross-cultural study in Italy and Portugal. Pediatric Reports, 5, 43 .

Rocha-Garcia A, Alvarez Del Rio A, Hernandez-Pena P, et al (2003). The emotional response of families to children with leukemia at the lower socio-economic level in central Mexico: a preliminary report. Psychooncol, 12, 78-90.

Shelly JA (1982). The Spiritual Needs of Children: A Guide for Nurses, Parents and Teachers. InterVarsity Press.

Smith J, Swallow V, Coyne I (2015). Involving parents in managing their child's long-term condition-a concept synthesis of family-centered care and partnership-in-care. J Pediatric Nurs, 30, 143-59.

Sposito AMP, Silva-Rodrigues FM, Sparapani VdC, et al (2015). Coping strategies used by hospitalized children with cancer undergoing chemotherapy. J Nurs Scholarship, 47, 143-51.

Taft TH, Ballou S, Keefer L (2012). Preliminary evaluation of maternal caregiver stress in pediatric eosinophilic gastrointestinal disorders. J Pediatric Psychol, 37, 523-32.

Taylor EJ, Mamier I (2005). Spiritual care nursing: what cancer patients and family caregivers want. $J A d v$ Nurs, 49, 260-7.

Thomson DR (2009). Growing in favor with God: Young children's spiritual development and implications for Christian education.

Witt WP, Litzelman K, Wisk LE, et al (2010). Stress-mediated quality of life outcomes in parents of childhood cancer and brain tumor survivors: a case-control study. Quality Life Res, 19, 995-1005.

Woodgate RL, Degner LF (2003). A substantive theory of keeping the spirit alive: The spirit within children with cancer and their families. J Pediatric Oncol Nurs, 20, 103-19.

Wray J, Lee K, Dearmun N, et al (2011). Parental anxiety and stress during children's hospitalisation: the stay close study. $J$ Child Health Care, 15, 163-74.

Zollfrank AA, Trevino KM, Cadge W, et al (2015). Teaching health care providers to provide spiritual care: A pilot study. $J$ Palliative Med, 18, 408-14. 